\title{
Experimental Heterotopic Heart Transplantation: An Easier Technique
}

\author{
J.R. Roda ${ }^{a}$ Lourdes Alvarez $^{\mathrm{b}} \quad$ G. Téllez $^{\mathrm{a}} \quad$ A. Cañas $^{\mathrm{a}} \quad$ E. Castedo ${ }^{\mathrm{a}} \quad$ J. Ugarte $^{\mathrm{a}}$ \\ J.L. Castillo-Olivares ${ }^{b}$
}

Departments of ${ }^{a}$ Cardiovascular Surgery and ${ }^{b}$ Experimental Surgery, University Hospital Puerta de Hierro, Madrid, Spain

\begin{abstract}
Aim: The use of heterotopic heart transplantation (HHT) in experimental surgery is an extended method to evaluate cardiac graft viability. To study endothelial injury after ischemia-reperfusion, the technique described by Matsui et al. in 1988 for HHT was chosen. A modification, which consists of replacing the atrium-to-atrium anastomosis for the tip of a 30-Fr venous cannula, was developed with the purpose of using this technique in small pigs. Both techniques were compared. Methods: Twenty-seven consecutive HHTs in $17-$ to $20-\mathrm{kg}$ pigs using Matsui's original technique and the modified technique were performed. Ischemia time, bleeding volume, mean gradient and anastomosis complications were measured to compare both techniques. Results: Statistically significant decreases in ischemia time, bleeding volume and mean gradient with the modified technique were found. Furthermore, there were two cases of suture dehiscence with the original technique. Conclusions: The replacement of the atrium-to-atrium anastomosis for the venous cannula is a modification that statistically decreases the ischemia time, blood loss and avoids suture complications. This modification makes Matsui's technique easier, faster and safer in small pigs and it may be used in bigger animals and in any kind of non-permanent anastomosis.
\end{abstract}

Copyright $(2004$ S. Karger AG, Basel

\section{Introduction}

Heterotopic heart transplantation (HHT) has become a useful method to study the viability of the cardiac graft in experimental surgery, independently of the consequences of extracorporeal circulation and with low cost. To study early oxidative stress and injury due to ischemia and reperfusion in Landrace $\times$ Large-White pig hearts, a model that allows to assess mechanical function of both ventricles was needed. There are several techniques describing HHT in pigs and among them the one described by Matsui et al. [1] was selected because of its simplicity, thoracic approach, no need for cardiopulmonary bypass, and it permits the recipient systemic circulation to be sustained by the graft.

Matsui's studies were performed on adult pigs weighing $30-60 \mathrm{~kg}$. In the original technique, the pulmonary trunk of the donor heart was anastomosed to the left atrial appendage for loading the left ventricle before the graft implant, and afterwards, the left atrium of the recipient's heart was attached to the right graft atrium during transplantation. The aorta anastomosis was performed with lateral clamping, end-to-side, to the descending aorta of the recipient animal (fig. 1).

After 4 HHTs were performed as control group, several modifications were introduced to adapt the technique for 17- to $20-\mathrm{kg}$ pigs. First, the approach to the descending

\begin{tabular}{ll}
\hline KARGER & ( ) 2004 S. Karger AG, Basel \\
0014-312X/04/0361-0064\$21.00/0 \\
$\begin{array}{l}\text { Fax +4161306 1234 } \\
\begin{array}{l}\text { E-Mail karger@karger.ch } \\
\text { www.karger.com }\end{array}\end{array}$ & $\begin{array}{l}\text { Accessible online at: } \\
\text { www.karger.com/esr }\end{array}$
\end{tabular}

Dr. J.R. Roda

Department of Cardiovascular Surgery, University Hospital Puerta de Hierro

San Martín de Porres 4

ES-28035 Madrid (Spain)

E-Mail rodajr@airtel.net 


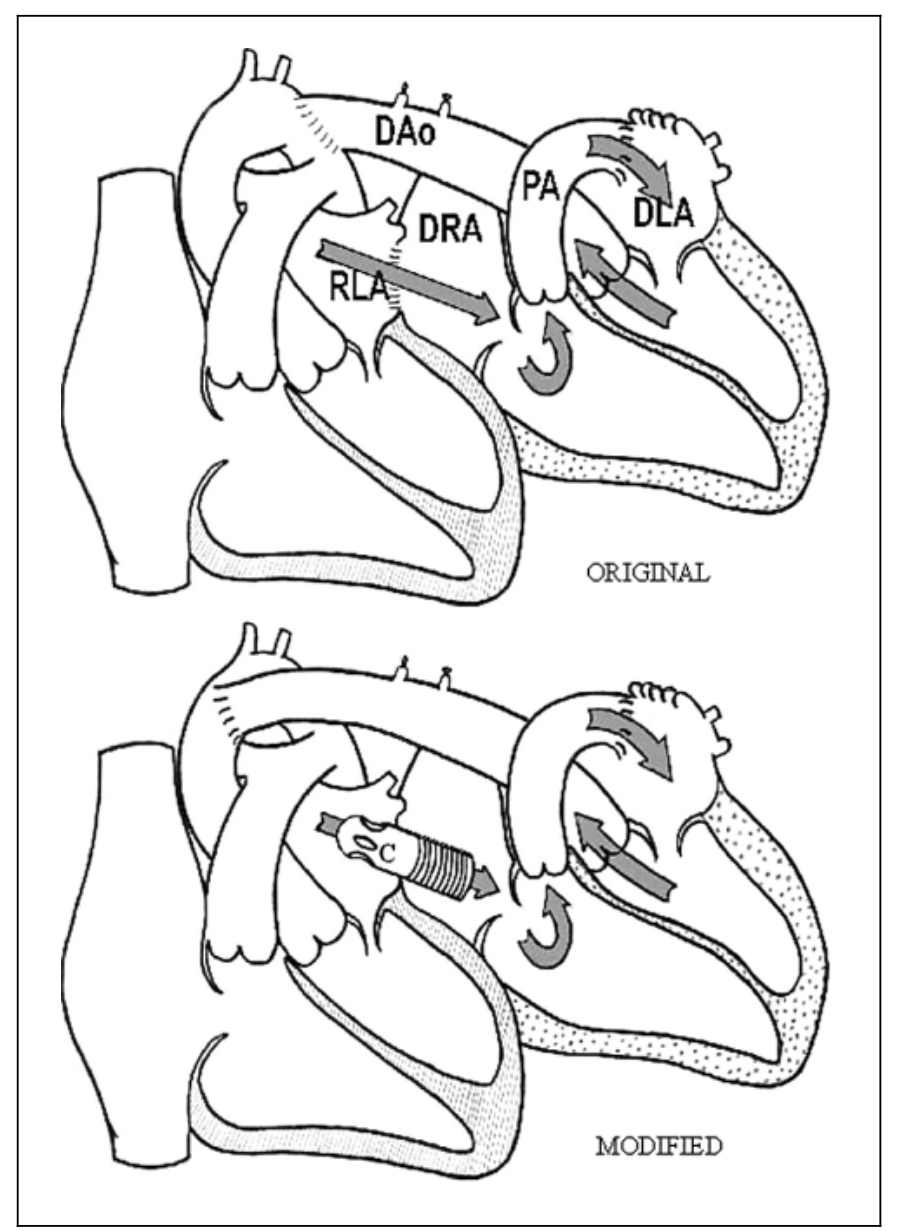

Fig. 1. Differences between both techniques: in the original technique the donor aorta is anastomosed to the descending aorta of the recipient pig and both atria are sutured. The modified one replaces the atrium-to-atrium anastomosis with a cannula and uses the ascending aorta. DAo $=$ Donor aorta; DRA = donor right atrium; $\mathrm{PA}=$ pulmonary artery; $\mathrm{DLA}=$ donor left atrium; $\mathrm{RLA}=$ recipient left atrium; $\mathrm{C}=$ cannula.

aorta through a median sternotomy in small pigs turned lateral clamping and end-to-side anastomosis into a complex maneuver due to lack of space. Second, because of weakness of the atrium wall, lateral clamping of the left atrium was insufficient to ensure a large enough anastomosis.

\section{Material and Methods}

A new technique, using the tip of a venous cannula (30-Fr William Harvey ${ }^{\circledR}$ Venous Cannula, C.R. Bard, Inc., Haverhill, Mass., USA), was developed as a bridge between both appendages to avoid the atrium-to-atrium anastomosis and performing the aorta-to-aorta

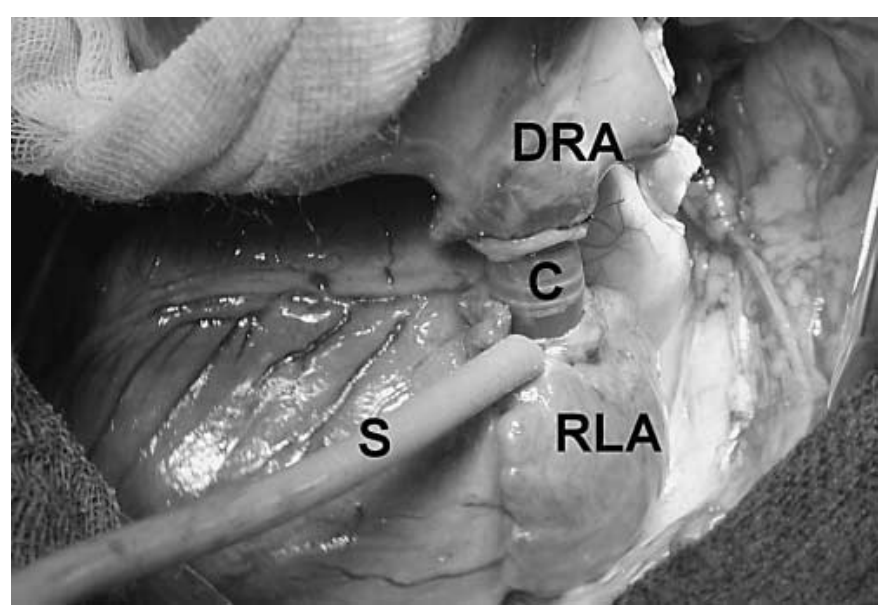

Fig. 2. The cannula connects both atria instead of the original anastomosis. $\mathrm{DRA}=$ Donor right atrium; $\mathrm{C}=$ cannula; $\mathrm{RLA}=$ recipient left atrium; $\mathrm{S}=$ snare.

anastomosis in the ascending instead of the descending aorta. Before the graft implant, the proximal end of the venous cannula was inserted into the right atrial appendage and attached using a pursestring suture.

Animals anesthetized with intravenous propofol $(9 \mathrm{mg} / \mathrm{kg} / \mathrm{h})$ and pancuronium bromide $(0.4 \mathrm{mg} / \mathrm{kg} / \mathrm{h})$ were subsequently intubated and ventilated with volume-controlled ventilators using $100 \% \mathrm{O}_{2}$. Carotid arterial and jugular venous catheters were placed for pressure monitoring and fluid infusion.

The recipient animal was approached through a median sternotomy and after the ascending aorta was mobilized widely, the end-toside aorta anastomosis was performed in the recipient's ascending aorta with Prolene ${ }^{\circledR}$ 4/0 running suture, using a lateral clamp. Afterwards, another purse-string suture was made in left atrial appendage with Prolene ${ }^{\circledR} 3 / 0$ and once it was opened, the distal tip of the cannula was inserted quickly to avoid blood loss and the suture was tied (fig. 2).

After the control group $(n=4), 27$ consecutive HHTs were prospectively randomized, using either the original technique $(n=9$, mean weigh $18.6 \pm 1.06 \mathrm{~kg})$ or the modified technique $(\mathrm{n}=18$, mean weight $18.7 \pm 0.95 \mathrm{~kg}$ ). In all cases, the ascending aorta of the recipient animal was used for the end-to-side anastomosis.

Ischemia time was measured in minutes since clamping the donor aorta, during extraction and preparation of the graft until removing the clamp after transplantation. Blood of the surgical field during the implantation procedure was collected and expressed in milliliters. The gradient of the suture or of the cannula between recipient left atrium and donor right atrium was calculated measuring pressures in millimeters of mercury in both atria.

Statistical analysis: Data are expressed as mean \pm SEM and the Student $t$ test analysis was used with a value of $p<0.05$ as statistically significant difference. 
Table 1. Our comparative data for Matsui's original technique versus the modified technique

\begin{tabular}{|c|c|c|c|}
\hline & $\begin{array}{l}\text { Original } \\
(\mathrm{n}=9)\end{array}$ & $\begin{array}{l}\text { Modified } \\
(\mathrm{n}=18)\end{array}$ & $\mathrm{p}$ value \\
\hline Ischemia time, $\min$ & $122 \pm 4.9$ & $98 \pm 1.8$ & $<0.01$ \\
\hline Bleeding, $\mathrm{ml}$ & $100 \pm 13.6$ & $60 \pm 6$ & $<0.05$ \\
\hline Dehiscence & 2 & 0 & \\
\hline Mean gradient, $\mathrm{mm} \mathrm{Hg}$ & $10.3 \pm 2$ & $2.1 \pm 0.5$ & $<0.01$ \\
\hline
\end{tabular}

\section{Results}

Ischemia time or length of the whole procedure (harvesting, preparation and implantation of the donor heart) decreased from 122 to $98 \min (\mathrm{p}<0.01)$ using the modified technique. Due to the absence of dehiscence or leak of the suture, there was a $40 \%$ reduction in blood loss $(\mathrm{p}<$ 0.05 ) when the cannula was used instead of the atriumto-atrium anastomosis. In the same way, mean gradient was significantly reduced in the cannula group because no suture stenosis is possible and cannula gradient is trivial. Results of the modified technique are resumed and compared with the original one in table 1 .

\section{Conclusions}

Matsui's HHT technique has an ideal concept for this kind of experimental surgery in 30- to 60-kg pigs, however $17-$ to $20-\mathrm{kg}$ pigs have a much smaller heart and weaker tissues. The replacement of the atrium-to-atrium anastomosis for the venous cannula had two purposes, namely to save time and avoid complications. The analysis of the results shows a significant decrease in ischemia time, blood loss and suture gradient, besides avoiding suture complications. This modified technique converts the original one into an easier, faster and safer technique in small pigs and it may be used in bigger animals and what is most important, in any kind of non-permanent anastomosis.

\section{Acknowledgement}

Supported by grant 00/0387 from Fondo de Investigación Sanitaria, Spain.

Reference

1 Matsui Y, Deleuze P, Kawasaki K, Léandri J, Loisance D: Experimental model of heterotopic cardiac transplantation for evaluation of graft viability and function. Eur Surg Res 1988; 20:161-167. 